Check for updates

The BMJ

Cite this as: $B M J 2021 ; 374: \mathrm{n} 2098$ http://dx.doi.org/10.1136/bmj.n2098 Published: 24 August 2021

\title{
Covid-19: $40 \%$ of patients with weakened immune system mount lower response to vaccines
}

Clara Munro

Four in 10 people who are clinically vulnerable generate lower levels of antibodies than healthy recipients after two shots of vaccine against SARS-CoV-2, a study has found. ${ }^{1}$

The Octave (Observational Cohort Trial T cells Antibodies and Vaccine Efficacy in SARS-CoV-2) trial is one of the largest in the world to have looked at the response to covid-19 vaccination in patients who are immunocompromised. It compared 600 patients, who had a weakened immune system because of their disease process or treatment, with the antibody response of healthy people from the Pitch (Protective Immunity from T Cells in Healthcare workers) study.

The trial included patients with solid organ and haematological cancers, end stage kidney and liver disease, organ transplants, and immune mediated inflammatory disease such as inflammatory bowel disease, vasculitis, or rheumatoid arthritis-patients who were not included in original vaccine trial data.

The findings, published as a preprint on the Lancet site, ${ }^{1}$ showed that $89 \%$ of immunocompromised patients seroconverted within four weeks of the second vaccine dose, as compared with $100 \%$ of healthy participants in the Pitch trial.

Overall, $60 \%$ of immunocompromised patients had an antibody response equivalent to that of healthy vaccine recipients, but $11 \%$ of those with a weakened immune system failed to generate any antibodies.

Failure to seroconvert was particularly high in certain groups: $72.4 \%$ of patients with ANCA associated vasculitis and $98 \%$ of patients with inflammatory arthritis were in this category. Notably, all of the patients with ANCA associated vasculitis had received rituximab, a targeted B cell depletion therapy, and the researchers suspect a possible link between low seroconversion and rituximab because of the importance of B cells in the immune response to covid-19.

\section{Immunological analysis}

The findings have been shared with the UK's Joint Committee on Vaccination and Immunisation, which is poised to decide on provision of booster vaccines in early September. Some countries that are already administering booster doses have prioritised people with chronic diseases or who are taking immunosuppressive therapies. ${ }^{2}$

Iain McInnes, chief investigator of Octave, clarified that this was an immunological analysis, looking at antibody and cellular (T cell) response, not a clinical effectiveness trial examining responses to specific vaccines or mixed doses.
While there was concern about the lack of seroconversion in some people, the researchers noted that these patients had a cellular (T cell) response, the body's "back-up" system. This suggests that the vaccine is immunologically active in all patients but that the type and quality of that response varies.

The trial, funded by the Medical Research Council, is a multicentre, UK-wide trial, led by the University of Glasgow and coordinated by the University of Birmingham's Cancer Research UK Clinical Trials Unit.

Kearns P, Siebert S, Willicombe M, et al. Examining the immunological effects of covid-19 vaccination in patients with conditions potentially leading to diminished immune response capacity. Preprints with the Lancet 2021 [preprint]. https://papers.ssrn.com/sol3/papers.cfm?ab-

stract_id=3910058"https://www.thelancet.com/preprints"

2 Mahase E. Covid-19 booster vaccines: What we know and who's doing what. BMJ 2021;374:n2082. doi: 10.1136/bmj.n2082 pmid: 34417167

This article is made freely available for use in accordance with BMJ's website terms and conditions for the duration of the covid-19 pandemic or until otherwise determined by BMJ. You may use, download and print the article for any lawful, non-commercial purpose (including text and data mining) provided that all copyright notices and trade marks are retained. 